\title{
A Time for Change: The Argument
}

\section{for National Pharmacare}
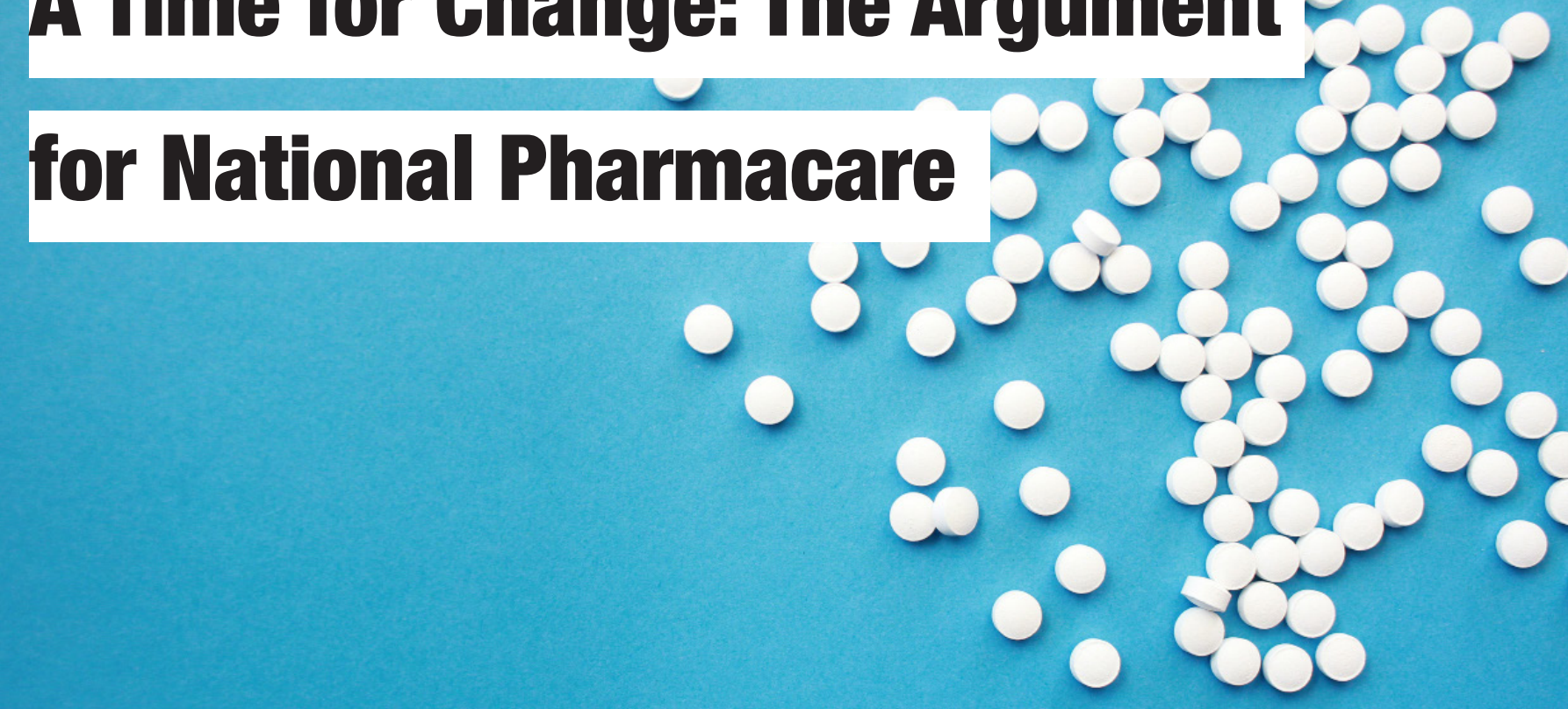
implementation of such a program. ${ }^{6}$ With such a troubled history and the unchanging political landscape towards the adoption of a national system, it is fair to ask why we should even care about Pharmacare? To answer this, we must take a hard look at our current system.

As of 2021 Canada remains the only country in the world with a national Medicare program that also doesn't have a national Pharmacare program to match. ${ }^{7} \mathrm{~A}$ fact that is even more alarming considering the near universal support, on both sides of the political spectrum, for such a program. With $90 \%$ of Canadians supporting the idea, this national desire is only matched by strong evidence that shows the failure of our current approach. ${ }^{8}$ According to the comprehensive final report from The Council, $19 \%$ of Canadians, around 7.5 million people, are either uninsured or underinsured in regard to pharmaceutical coverage. Naturally, this lack of coverage has led Canada to have a 2-5 times higher non-adherence rate for pharmaceuticals in comparison to countries with a national program. ${ }^{7}$ This non-adherence accounts for $5 \%$ of all hospital admissions, costing our healthcare system $\$ 4$ billion dollars alone before factoring in increased long-term costs stemming from these admissions. ${ }^{9}$ The cost of our current Pharmacare system is unfortunately one that is measured in both dollars and potential lives.

As aforementioned, Canadian drug prices have ballooned; while globally prices have increased, Canada has been particularly affected. According to The Council, Canada pays the third highest prices for branded drugs among 34 countries mostly in Europe and North America; this disparity can be directly linked to our inability to negotiate drug prices due to, once again, our lack of a national Pharmacare plan. Instead of one cooperative plan to represent nearly 40 million Canadians, we are fixed in a system where a patchwork of plans forces a dilution of our negotiating power. ${ }^{7}$ Thereby, only further highlighting holes in our system. It is apparent that the current system is both ineffective in providing comprehensive care for patients and giving Canadians a fair price on their medications.

If the present shortcomings of our system were a keg of gunpowder, the COVID-19 pandemic surely represents the match. Unemployment has hit a dramatic high because of the pandemic; the country saw a $5.2 \%$ jump in unemployment, a jump reminiscent of the 1980's depression..$^{10}$ As of 2021, the employment rate has yet to recover to pre-pandemic numbers and with this comes the reality that many Canadians have lost their vital job-based coverage. Moreover, the pandemic has led to a widespread decrease in proper nutrition, decrease in exercise and an increase in alcoholism, ${ }^{11,12}$ all factors that could lead to an increased need for medications. The pandemic has hit Canadian Pharmacare with the proverbial double whammy, through a decrease in coverage of drugs and an increase in the need for medications.

While one may argue that focusing on Pharmacare would be impossible with the way the pandemic has decimated the Canadian economy, it is in these generational events that we see the greatest potential for change. The great depression brought about one of the greatest periods of social reform in the United States, a revolution that was mirrored on this side of the border as well. I believe that now is the best time to push for the reform of this glaring weakness in our healthcare system. I am sending this commentary to the MP's in my voting district back home in Hamilton (David Sweet) and my MP here in Ottawa (David McGuinty), members of the Conservatives and the Liberals, respectively. I do this because this is an issue that affects all of us, no matter our politics; I challenge you to do the same. Through resilience, drive, and collective efforts we can reform this program and create a true universal healthcare system for all Canadians.

\section{REFERENCES}

1. Morgan S, Daw J. Canadian Pharmacare: Looking Back, Looking Forward. Healthcare Policy I Politiques de Santé [Internet]. 2012 [cited 28 March 2021];8(1):14-23. Available from: https://www.ncbi.nlm.nih.gov/pmc/articles/ PMC3430151/\#R14

2. National Health Expenditure Trends, 1975 to 2012 [Internet]. 2012 [cited 28 March 2021]. Available from: https://secure. cihi.ca/free_products/NHEXTrendsReport2012EN.pdf

3. Daw J, Morgan S. Stitching the gaps in the Canadian public drug coverage patchwork? A review of provincial pharmacare policy changes from 2000 to 2010. Health Policy [Internet]. 2012 [cited 28 March 2021];104(1):19-26. Available from: https://pubmed.ncbi.nlm.nih.gov/21978939/

4. Xing L. Here are the changes the Ford government has put in place for April 1 I CBC News [Internet]. CBC. 2019 [cited 28 March 2021]. Available from: https://www.cbc.ca/news/ canada/toronto/doug-ford-changes-april-first-1.5076199

5. McSheffrey E. Nova Scotia Liberal MPs decry NDP 'political stunt' after voting down bill on national pharmacare [Internet]. Global News. 2021 [cited 28 March 2021]. Available from: https://globalnews.ca/news/7662309/nova-scotia-liberalsndp-national-pharmacare/

6. Thibedeau H. Liberals aren't setting aside enough cash yet 
for pharmacare, says advisory panel chair I CBC News [Internet]. CBC. 2019 [cited 28 March 2021]. Available from: https://www.cbc.ca/news/politics/pharmacare-hoskinstrudeau-liberals-1.5311601

7. Hoskins E, Caron N, Dumez V, Homsy M, Orridge C, Whalen D et al. Final Report of the Advisory Council on the Implementation of National Pharmacare [Internet]. Health Canada; 2019. Available from: https://www.canada.ca/ en/health-canada/corporate/about-health-canada/publicengagement/external-advisory-bodies/implementationnational-pharmacare/final-report.html

8. Angus Reid Institute. Access for all: Near universal support for a pharmacare plan covering Canadians' prescription drug costs [Internet]. Angus Reid Institute; 2020. Available from: https://angusreid.org/pharmacare-2020/

9. Costs of medication non-adherence [Internet]. Medavie Blue Cross. 2020 [cited 28 March 2021]. Available from: https:// www. medaviebc.ca/en/insights/posts/medication-nonadherence

10. Statistics Canada. Labour Force Survey, April 2020 [Internet]. Statistics Canada; 2020. Available from: https://www150. statcan.gc.ca/n1/daily-quotidien/200508/dq200508a-eng. htm

11. Caputo E, Reichert F. Studies of Physical Activity and COVID-19 During the Pandemic: A Scoping Review. Journal of Physical Activity and Health [Internet]. 2020 [cited 28 March 2021];17(12):1275-1284. Available from: https:// journals.humankinetics.com/view/journals/jpah/17/12/ article-p1275.xml

12. Wardell J, Kempe T, Rapinda K, Single A, Bilevicius $\mathrm{E}$, Frohlich $\mathrm{J}$ et al. Drinking to Cope During COVID-19 Pandemic: The Role of External and Internal Factors in Coping Motive Pathways to Alcohol Use, Solitary Drinking, and Alcohol Problems. Alcoholism: Clinical and Experimental Research [Internet]. 2020 [cited 28 March 2021];44(10):2073-2083. Available from: https:// onlinelibrary.wiley.com/doi/full/10.1111/acer.14425?casa token=dmHAD5SWCU4AAAAA\%3AztroeS5_rGwEeC_ PrEV2yXXtOfHPUEToJqo-DMmt1CMVZReGjLceqCPZB8fw uF5RODrwu9HVb9jGwio 